\title{
Efeito do ambiente de produção sobre frangos de corte sexados criados em galpão comercial
}

\author{
[Effect of the production environment on sexed broilers reared in a \\ commercial house] \\ A.G. Amaral ${ }^{1}$, T. Yanagi Junior ${ }^{1}$, R.R. Lima $^{2}$, V.H. Teixeira ${ }^{1}$, L. Schiassi ${ }^{1}$ \\ ${ }^{1}$ Departamento de Engenharia -UFLA \\ Caixa Postal 3037 \\ 37.200-000 - Lavras, MG \\ ${ }^{2}$ Departamento de Ciências Exatas - UFLA - Lavras, MG
}

\begin{abstract}
RESUMO
Avaliou-se o efeito do ambiente de produção sobre o desempenho produtivo e respostas fisiológicas de frangos de corte de marca comercial sexados, machos e fêmeas. Os frangos foram criados em duas alas separadas no interior de um galpão comercial com sistemas de ventilação convencional e nebulização. O ambiente produtivo foi avaliado por meio do índice de temperatura do globo negro e umidade, da intensidade de ruído e do nível de iluminância. A avaliação dos animais foi feita por meio das respostas fisiológicas - frequência respiratória, temperatura retal, temperatura da pele e temperatura da pena - e produtivas - ganho de peso semanal, massa corporal e mortalidade. Os machos apresentaram desempenho produtivo superior às fêmeas $(\mathrm{P}<0,05)$. A massa corporal média dos machos foi $214,6 \mathrm{~g}$ maior que a das fêmeas aos 35 dias de vida, a qual se igualou à massa corporal dos machos somente aos 38,47 dias de vida. As respostas fisiológicas não se relacionaram com o ambiente.
\end{abstract}

Palavras-chave: frango de corte, ambiente termoacústico, iluminância, desempenho

\begin{abstract}
The effect of the production environment on the productive performance and physiological responses of sexed broiler chickens, male and female, was evaluated. The birds were raised in two separate regions inside the broiler house. The productive environment was determined using the black-globe temperature humidity index, as well as noise and luminance levels. The physiological responses (breath rate, rectal temperature, skin temperature and feather temperature) and productive responses (weekly weight gain, body mass and mortality) were used to evaluate the effect of the production environment on the broilers raised in a house equipped with conventional and misting ventilation systems. The mean body mass of the males was $214.6 \mathrm{~g}$ greater than females at 35 days of life, which became equal to the male mean body mass only at 38.47 days of life. The physiological responses were not related to the environment.
\end{abstract}

Keywords: broiler, thermo acoustic environment, luminance, performance

\section{INTRODUÇÃO}

O ambiente de produção exerce papel fundamental na avicultura moderna, que busca alcançar alta produtividade, em espaço físico e tempo relativamente reduzidos. Dentre outros fatores do ambiente, os térmicos, representados por temperatura, umidade, velocidade do ar e radiação, são os que mais afetam os animais, pois comprometem a função vital mais importante das aves, que é a homeotermia.

Aves submetidas a condições ambientais desfavoráveis apresentam comportamentos alimentar e físico característicos. A exposição de frangos a altas temperaturas causa redução na

Recebido em 13 de maio de 2010

Aceito em 4 de abril de 2011

E-mail: adrianagamaral@gmail.com 
ingestão de alimentos, prejudicando a taxa de crescimento, o rendimento do peito e a qualidade da carne, além de provocar dispêndio de energia da produção para promover a perda de calor (Dozier et al., 2006; Lu et al., 2007). Quando submetidos à temperatura ambiente cíclica elevada, frangos de corte apresentam aumento da frequência respiratória (FR) e da temperatura retal (TR), alcançando $160,4 \mathrm{mov} \mathrm{min}^{-1}$ e 42,9 ${ }^{\circ} \mathrm{C}$ aos 35 dias de idade, respectivamente (Marchini et al., 2007).

Para Furlan (2006), ajustes de comportamento podem ocorrer mais rapidamente e com menor dispêndio de energia do que muitas respostas fisiológicas, como a redução das atividades físicas, pois, quando as aves permanecem sentadas e com as asas abertas,aumentam a dissipação de calor pela maximização da área de superfície corporal.

As condições de conforto térmico são função de diversas variáveis e podem ser avaliadas pelos índices de conforto e desconforto térmico. O índice de temperatura do globo negro e umidade (ITGU) vem sendo amplamente utilizado por considerar, em um único valor, os efeitos da temperatura de bulbo seco, da umidade relativa, da radiação e da velocidade do ar (Buffington et al., 1981). Segundo Medeiros et al. (2005), em ambientes considerados quentes, ITGU $>77$, mesmo sem haver mortalidade, ocorre redução de $67 \%$ no ganho de peso diário. Além dos fatores térmicos, a iluminância e a intensidade de ruído influenciam significativamente o desempenho de frangos de corte. Aves mantidas em intensidade luminosa reduzida, até 5 Lux m ${ }^{-2}$, consomem mais ração, o que resulta em aumento do peso vivo, quando comparadas às expostas a 20 Lux m$^{-2}$ (Downs et al., 2006).

A influência do ambiente térmico nas aves varia com a espécie, idade, peso corporal, sexo, atividade física e consumo alimentar. Ao avaliarem o efeito do sexo no desempenho de linhagens comerciais de frangos de corte, Stringhini et al. (2003) verificaram melhor desempenho e maior peso de carcaça nos machos. Com base no exposto, o objetivo da presente pesquisa foi avaliar o efeito do ambiente de produção sobre o desempenho produtivo e sobre respostas fisiológicas de frangos de corte sexados, machos e fêmeas, criados em galpão comercial convencional.

\section{MATERIAL E MÉTODOS}

O presente experimento foi realizado em uma granja comercial de frangos de corte, entre os dias 6 de fevereiro e 4 de março de 2009, do $21^{\circ}$ ao $46^{\circ}$ dia de vida.

Usou-se um galpão, orientado na direção lesteoeste (Fig. 1), de 2,5m de pé-direito, cobertura de telhas de cimento amianto de $0,004 \mathrm{~m}$ de espessura, piso de concreto, cama de serragem, cortinas laterais e forro de lona plástica na cor azul e amarela, respectivamente. Os frangos de corte foram submetidos a um programa contínuo de luz (24L:0E), e o galpão foi dividido, por meio de chapas de compensado, em três alas, ala $\mathrm{M}$, ala $\mathrm{F}$ e ala $\mathrm{R}$, destinadas a machos, fêmeas e refugos, respectivamente, as duas primeiras com densidades médias de 20,99 fêmeas $\mathrm{m}^{-2}$ e 19,70 machos $\mathrm{m}^{-2}$.

O sistema de arrefecimento térmico do ambiente de criação adotado foi o do tipo convencional, com cortinas laterais abertas continuamente, contando com sistema de ventilação, composto por 20 ventiladores (112 cv de potência cada e vazão de $240 \mathrm{~m}^{3} \mathrm{~min}^{-1}$ ), associado a um sistema de nebulização (Fig. 1). O sistema de nebulização é composto por duas linhas equipadas com 10 nebulizadores $\left(7 \pm 1,8 \mathrm{~L} \mathrm{~h}^{-1}\right)$ cada.

Foram utilizados frangos de corte de linhagem comercial, 13.500 machos e 13.000 fêmeas, dos 21 aos 35 dias para fêmeas e dos 21 aos 46 dias para os machos, tendo em vista que as fêmeas foram abatidas aos 36 dias de idade e os machos aos 46 dias. Aos 16 dias de vida, cerca de 2.000 aves foram destinadas à ala especificada como refugos, em razão de sua baixa massa corporal em relação ao restante do lote. Estas aves não foram consideradas na presente pesquisa. Durante a fase experimental, as aves tiveram acesso ad libitum à água e à ração. 


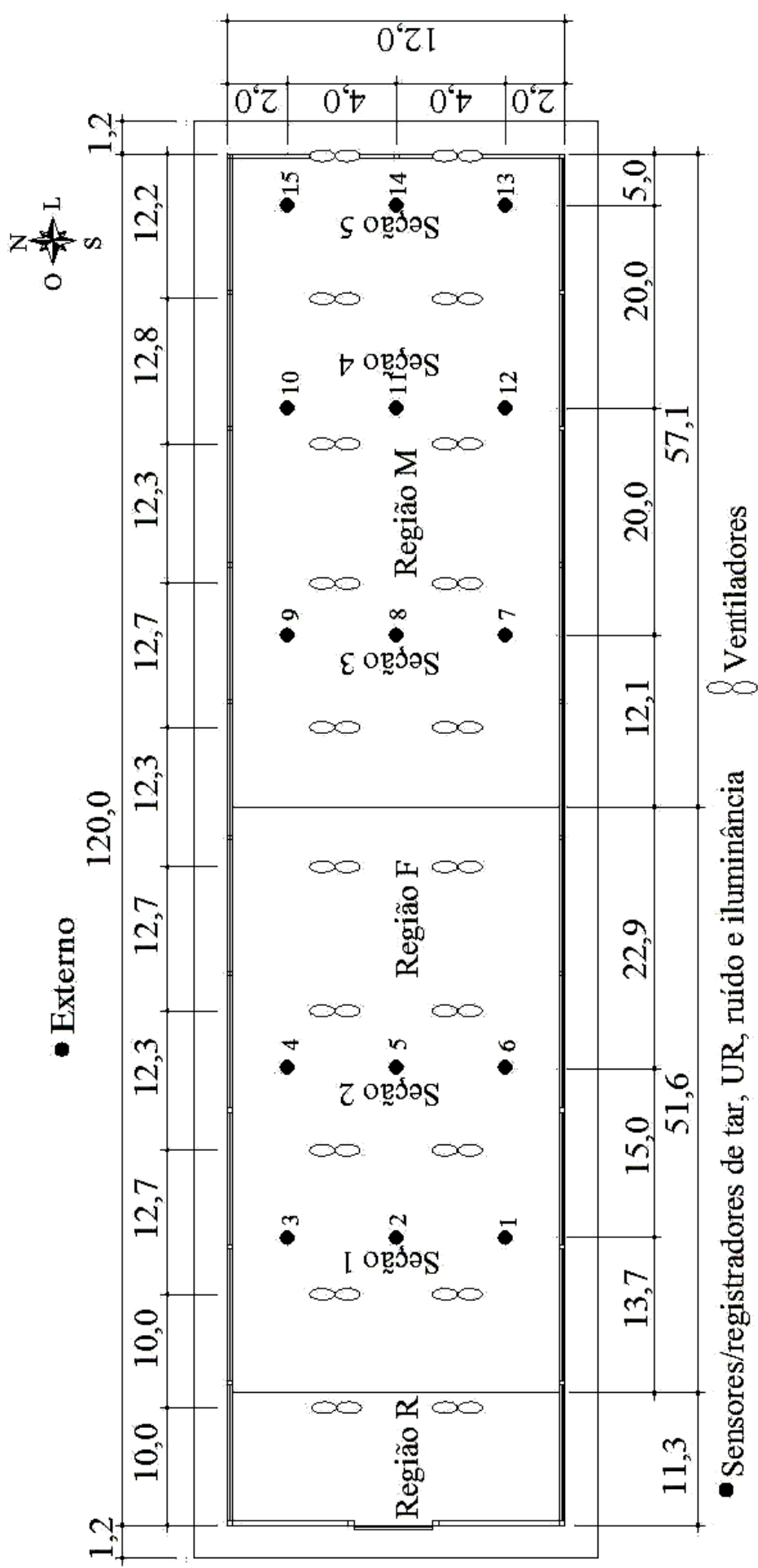

Figura 1. Esquema do galpão utilizado no experimento. Unidade de cotagem: metros.

O ITGU foi utilizado para avaliação do ambiente térmico por ser o índice de utilização mais difundido no Brasil, pois, além de quantificar indiretamente a velocidade do ar, quantifica a carga térmica de radiação. Os valores de ITGU foram calculados a cada 10min, em função dos 
dados de $t_{g n}$ e $t_{p o}$ medidos, por meio da equação proposta por Buffington et al. (1981): ITGU = $\mathrm{t}_{\mathrm{gn}}$ $+0,36 \mathrm{t}_{\mathrm{po}}-330,08$, em que: $\mathrm{t}_{\mathrm{gn}}=$ temperatura de globo negro $(K)$ e $t_{p o}=$ temperatura de ponto de orvalho (K). Segundo Buffington et al. (1981), o ITGU é um indicador mais preciso do conforto térmico e da produção animal quando comparado ao índice de temperatura e umidade (ITU) em condições ambientais em que a radiação solar, ou a movimentação do ar são altas, e sob condições moderadas de radiação solar, são igualmente eficientes. Para Sampaio et al. (2004), a utilização do ITGU representa melhor a realidade das condições climáticas nas regiões com maior taxa de radiação solar quando comparado ao ITU. Diversos trabalhos têm usado o ITGU para avaliação e classificação do ambiente térmico (Oliveira et al., 2006; Abreu et al., 2007; Menegali et al., 2009; Nazareno et al., 2009).

O peso vivo de uma amostra de frangos de corte, 100 aves aproximadamente, foi determinado semanalmente, aos 21, 28, 35 dias para machos e fêmeas e aos 42 dias para os machos, e as médias foram calculadas a posteriori. A ocorrência de mortes foi monitorada diariamente, e esses dados foram usados para determinar a mortalidade acumulada a partir dos 21 dias de idade.

FR, TR, temperatura da pena $\left(\mathrm{T}_{\text {pena }}\right) \mathrm{e}$ temperatura da pele ( $\left.\mathrm{T}_{\text {pele }}\right)$, e o comportamento geral dos frangos foram avaliados semanalmente, em dois períodos distintos do dia, manhã e tarde, das oito horas às $10 \mathrm{~h} 30 \mathrm{~min}$ e das 13 horas às 15h30min, em uma ave escolhida aleatoriamente, próximo a cada um dos sensores instalados, totalizando, assim, três aves por seção, resultando na avaliação comportamental de seis fêmeas e nove machos a cada período, constituindo as repetições para caracterização do comportamento dentro do fator sexo. As fêmeas foram avaliadas dos 21 aos 35 dias de idade, e os machos dos 21 aos 42 dias. A TR foi medida por meio de um termômetro digital (precisão de $\pm 0,2^{\circ} \mathrm{C}$ ). A $\mathrm{T}_{\text {pena }}$ e a $\mathrm{T}_{\text {pele }}$ foram mensuradas por meio de um termômetro infravermelho (precisão de $\pm 0,1^{\circ} \mathrm{C}$ ) com controle de emissividade, configurado para 0,95, e mira laser. A FR foi determinada por observação visual direta durante 15s, sendo posteriormente este valor extrapolado para um minuto.

A análise do ambiente térmico foi feita de forma descritiva, utilizando-se gráficos Box-plot dos valores observados, além da utilização de medidas de posição e dispersão, como média, mediana e desvio-padrão. As respostas fisiológicas e o desempenho produtivo foram avaliados utilizando-se a análise de variância por meio do programa computacional SISVAR (Ferreira, 2000). O delineamento experimental foi o inteiramente ao acaso, sendo que, no caso do desempenho produtivo, os tratamentos se apresentaram em um arranjo fatorial 3x2, três idades: 21, 28 e 35, e dois sexos: machos e fêmeas.

\section{RESULTADOS E DISCUSSÃO}

Pelo comportamento dos valores de ITGUs nos 15 pontos de medição distribuídos ao longo do galpão e entre as alas (Fig. 2), observou-se que o ambiente térmico mostrou-se uniforme, o que possibilitou a comparação de desempenho entre os frangos, de uma forma generalizada no interior de toda a instalação, pois as aves estavam submetidas a condições de estresse por calor, caracterizado por valores de ITGU acima de 77 (Medeiros et al., 2005). Para a variável iluminância, a média encontrada foi de $817 \pm 633$ Lux m ${ }^{-2}$, máxima de 4980 Lux m ${ }^{-2}$ e mínima de $10 \mathrm{Lux} \mathrm{m}^{-2}$. Esta alta variação pode ser atribuída ao sistema produtivo, ou seja, galpão convencional com cortinas continuamente abertas. A intensidade de ruído situou-se em torno de $73 \pm 7 \mathrm{dBA}$, com valor máximo de 100dBA e mínimo de 35dBA. Os valores mínimos e máximos são atribuídos aos períodos em que o sistema de arrefecimento do ar estava desligado e acionado, respectivamente.

No $21^{\circ}$ e $35^{\circ}$ dias, as aves estavam submetidas a condições de desconforto térmico no período da tarde (Fig. 3), o que não ocorreu pela manhã, quando se encontravam em condições de conforto térmico. No $28^{\circ}$ dia, as aves encontravam-se em condições de conforto térmico nos dois períodos do dia. 


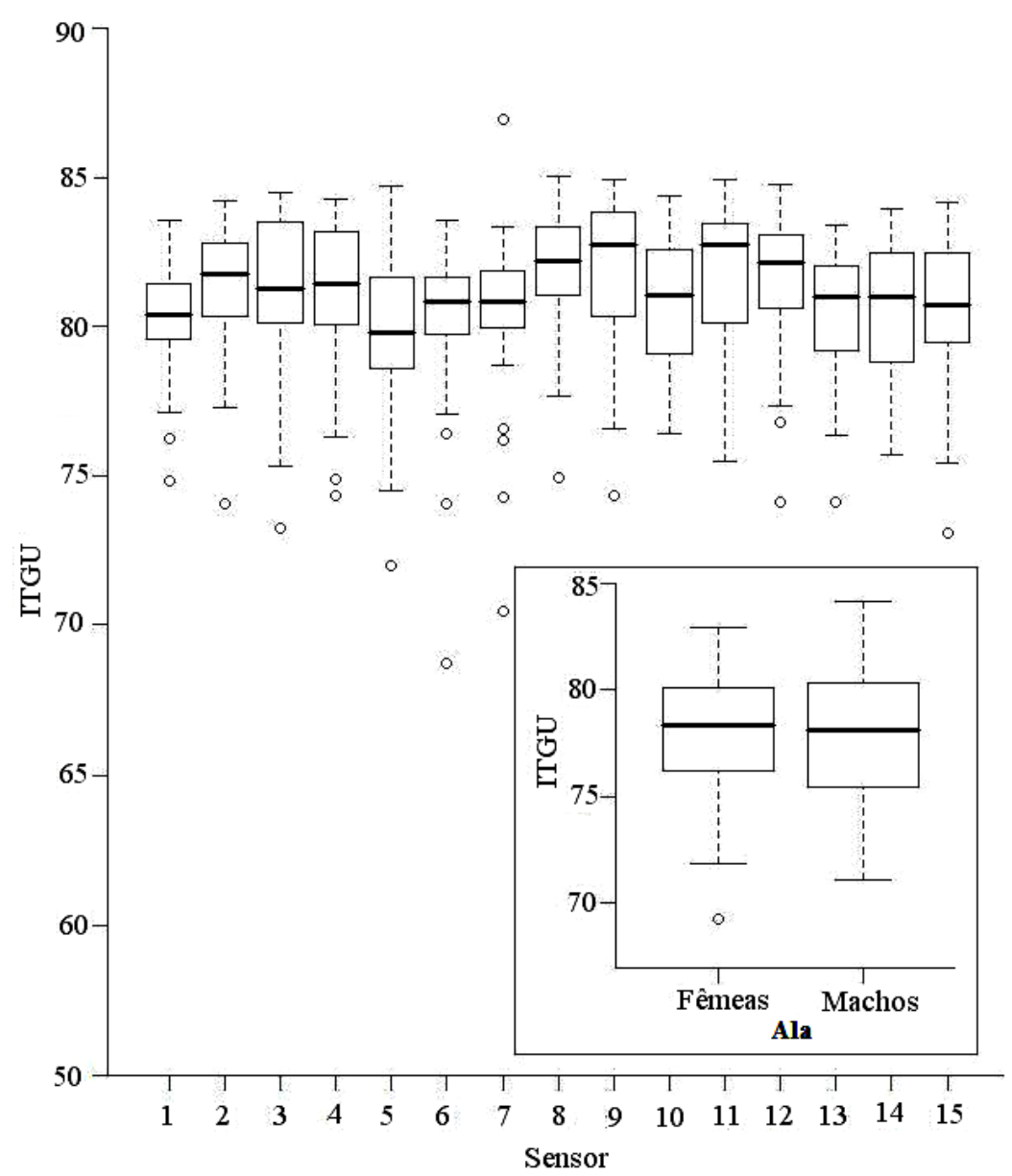

Figura 2. Índice de temperatura do globo negro e umidade (ITGU) nos 15 pontos distribuídos ao longo do galpão e entre as alas com machos e fêmeas alojados.

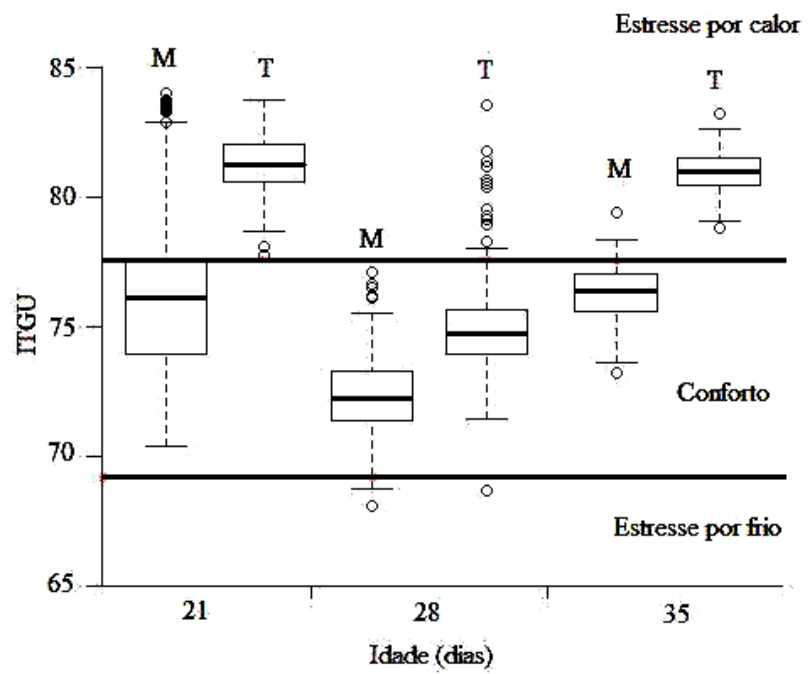

Figura 3. Valores médios do índice de temperatura do globo negro e umidade (ITGU) observados em galpão nos períodos da manhã $(\mathrm{M})$ e da tarde $(\mathrm{T})$, segundo a idade das aves. 
A FR (Fig. 4) diferiu significativamente ( $\mathrm{R} 0,01)$ entre os períodos da manhã e da tarde (Fig. 4A) e

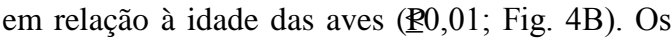
menores valores de FR observados durante o período da manhã, com mediana de $60 \mathrm{mov} \mathrm{min}^{-1}$, e maiores, observados no período da tarde, com mediana de $68 \mathrm{mov} \min ^{-1}$, devem-se às condições térmicas gerais observadas nos dois períodos nos quais esta variável foi avaliada, ou seja, conforto e estresse por calor (Fig. 3), respectivamente. No

A.

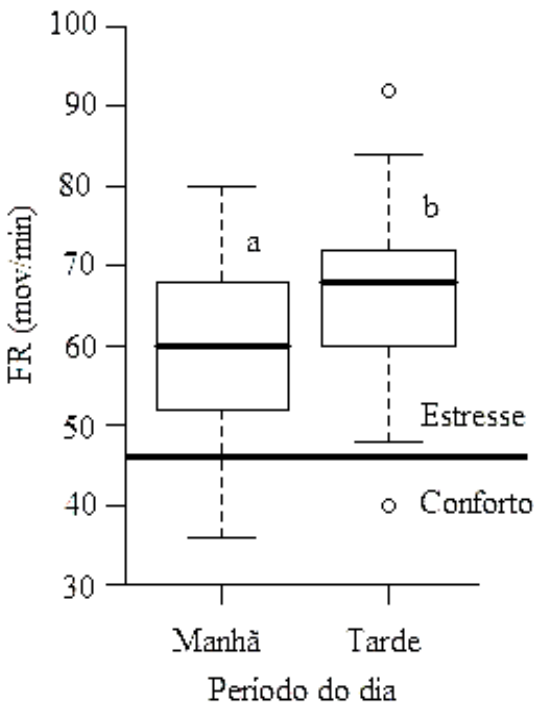

período da manhã, mesmo sob condições de conforto térmico, a FR observada foi mais alta que as observadas em outras pesquisas, que foram de 47 mov $\min ^{-1}$ (Medeiros et al., 2005; Marchini et al., 2007). Observou-se (Fig. 4B) tendência de os valores de FR ao longo dos dias de observação serem similares às condições térmicas observadas (Fig. 3), com declínio no $28^{\circ}$ dia em função das condições climáticas.

B.

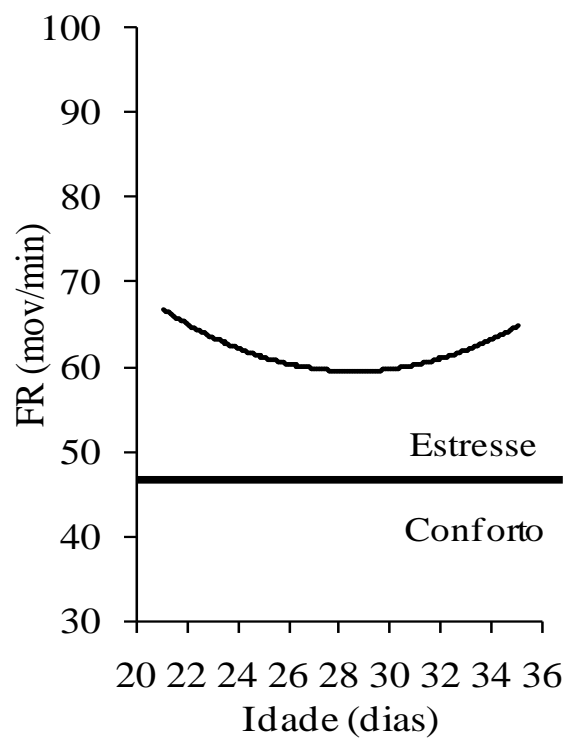

Figura 4. Valores médios de frequência respiratória (FR) de frangos de corte em função (A) do período de coleta e (B) da idade dos frangos de corte. Médias seguidas de letras distintas diferem entre si $(\mathrm{P}<0,05)$ pelo teste $\mathrm{F}$.

Para a variável TR (Fig. 5), a interação período versus idade apresentou diferenças significativas $(\mathrm{P} \leq 0,01)$, ou seja, os valores mantiveram-se abaixo do limite de conforto, que, segundo Medeiros et al. (2005) e Marchini et al. (2007), é de $41,4^{\circ} \mathrm{C}$ para ambientes termoneutros, e para Silva et al. (2007b) é de $41,1^{\circ} \mathrm{C}$. Apesar de os resultados não terem indicado estresse, deve-se ressaltar que a TR varia bruscamente apenas quando a temperatura ambiente atinge rapidamente $30^{\circ} \mathrm{C}$. Se a temperatura ambiente eleva-se gradativamente, a $\mathrm{t}_{\text {retal }}$ mantém-se constante até atingir $33^{\circ} \mathrm{C}$ (Boone e Hughes, 1971). Apesar de os valores médios observados para TR estarem abaixo do limite de conforto, os maiores valores, observados no período da tarde, do $21^{\circ}$ ao $35^{\circ}$ dia refletem os valores de ITGU obtidos (Fig. 3 ). Ainda, mesmo que os valores de TR indicassem que as aves estavam em conforto, a FR sugeria que as aves já expressavam certo desconforto térmico. Essa aparente contradição deve-se ao fato de que o aumento da FR se dá de forma mais rápida do que o aumento da TR, constituindo, dessa maneira, um modo consistente de avaliar o estado de conforto dos animais.

Com relação à $\mathrm{T}_{\text {pena }}$ (Fig. 6), houve diferença significativa entre sexos nas idades de 21 e 28 dias, sendo que a $\mathrm{T}_{\text {pena }}$ dos machos foi mais alta que a das fêmeas $(\mathrm{P}<0,01)$. Este fato pode ser explicado pelo melhor empenamento das fêmeas no dorso em relação ao dos machos (Silva et al., 2007a). Dessa forma, o valor da $T_{\text {pena }}$ dos machos, medido na região do dorso, pode ter sido influenciado pela $\mathrm{T}_{\text {pele. }}$. Ressalta-se, ainda, que a $\mathrm{T}_{\text {pena }}$ depende fortemente da velocidade do ar, devido às trocas de calor que ocorrem por convecção. Dessa maneira, esta variável não é a mais adequada para avaliação do estado de conforto térmico de aves. Similarmente às respostas fisiológicas anteriores, o comportamento da $t_{\text {pena }}$ seguiu aproximadamente $o$ do ITGU (Fig. 3). 


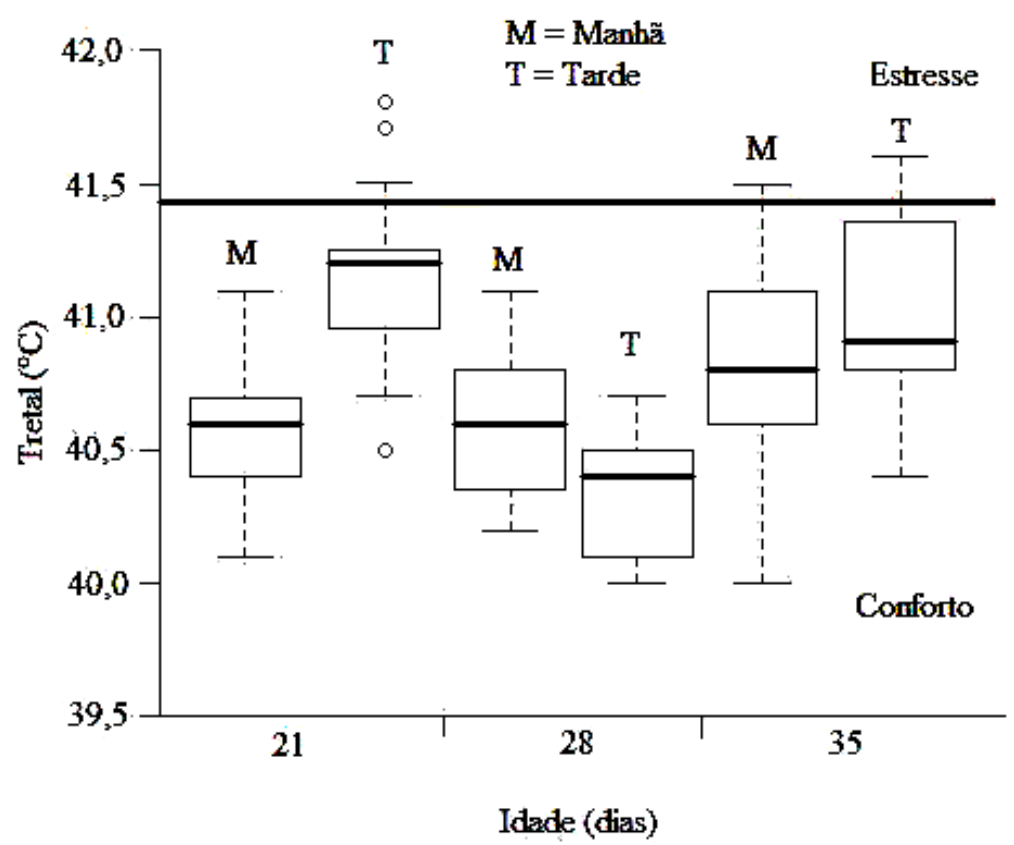

Figura 5. Temperatura retal de frangos de corte (TR) segundo o período dos dias avaliado, em função da idade.

Para a $\mathrm{T}_{\text {pele }}$ (Fig. 7), a interação período do dia versus sexo foi significativa $(\mathrm{P} \leq 0,01)$, sendo que o desdobramento da variável sexo mostrou que a $\mathrm{T}_{\text {pele }}$ dos machos foi mais alta que a das fêmeas no período da manhã. Isto se deve ao fato de que, pela manhã, as condições térmicas no interior do galpão eram mais amenas (Fig. 3), e como os machos apresentam menor empenamento, eles perdem mais calor para o ambiente ao seu redor, necessitando, dessa maneira, aumentar a sua produção de calor.

Verificou-se, ainda, efeito significativo da interação idade versus sexo $(\mathrm{P} \leq 0,01)$, ou seja, a $\mathrm{T}_{\text {pele }}$ dos machos aos 21 e 28 dias foi mais alta que a das fêmeas. A inversão observada no $35^{\circ}$ dia pode ser atribuída ao fato de terem sido avaliadas aves diferentes, com diferentes empenamentos, uma vez que eram apanhadas de forma aleatória.

Nas Fig. 8 e 9A, observa-se maior massa corporal nos machos em todo o período estudado $(\mathrm{P} \leq 0,01)$, semelhante a resultados de outros experimentos, em que os valores de peso e ganho de peso das fêmeas foram sempre mais baixos que os dos machos (Leandro et al., 2006; Longo et al., 2006). Portanto, visando acompanhar a tendência internacional com relação às exigência de tamanho, a massa corporal pode ser garantida pela sexagem dos animais, pois fêmeas e machos atingem pesos vivos diferentes no final do ciclo produtivo. Ainda, os ganhos de pesos para machos e fêmeas foram mais altos entre o $28^{\circ} \mathrm{e}$ 35 dias de idade (Fig. 9B).

As taxas de mortalidade total durante o período experimental - 21 a 35 dias - foram de $0,92 \%$ e 0,85\% para machos e fêmeas, respectivamente; já no período de 36 a 46 dias, a taxa de mortalidade entre os machos foi de $1,15 \%$.

A análise do comportamento dos frangos de corte (Fig. 10) mostra que as aves permaneceram prostradas no $21^{\circ}$ e $35^{\circ}$ dias, principalmente à tarde, período que se caracterizou por apresentar valores de ITGU superiores ao limite de conforto (Fig. 3). Ao longo de todos os dias, o comportamento mais evidenciado foi o de permanecerem deitadas, variação de 40 a $80 \%$ do tempo, nos diferentes dias de observação. Comportamento semelhante foi observado por Bizeray et al. (2002), ao relatarem que frangos de corte, independentemente da idade, gastam de 60 a $80 \%$ do tempo em descanso. O comportamento em permanecer prostrada nos dias de maior ITGU foi mais evidente, demonstrando, assim, a condição de estresse a que as aves estavam submetidas. 
Amaral et al.

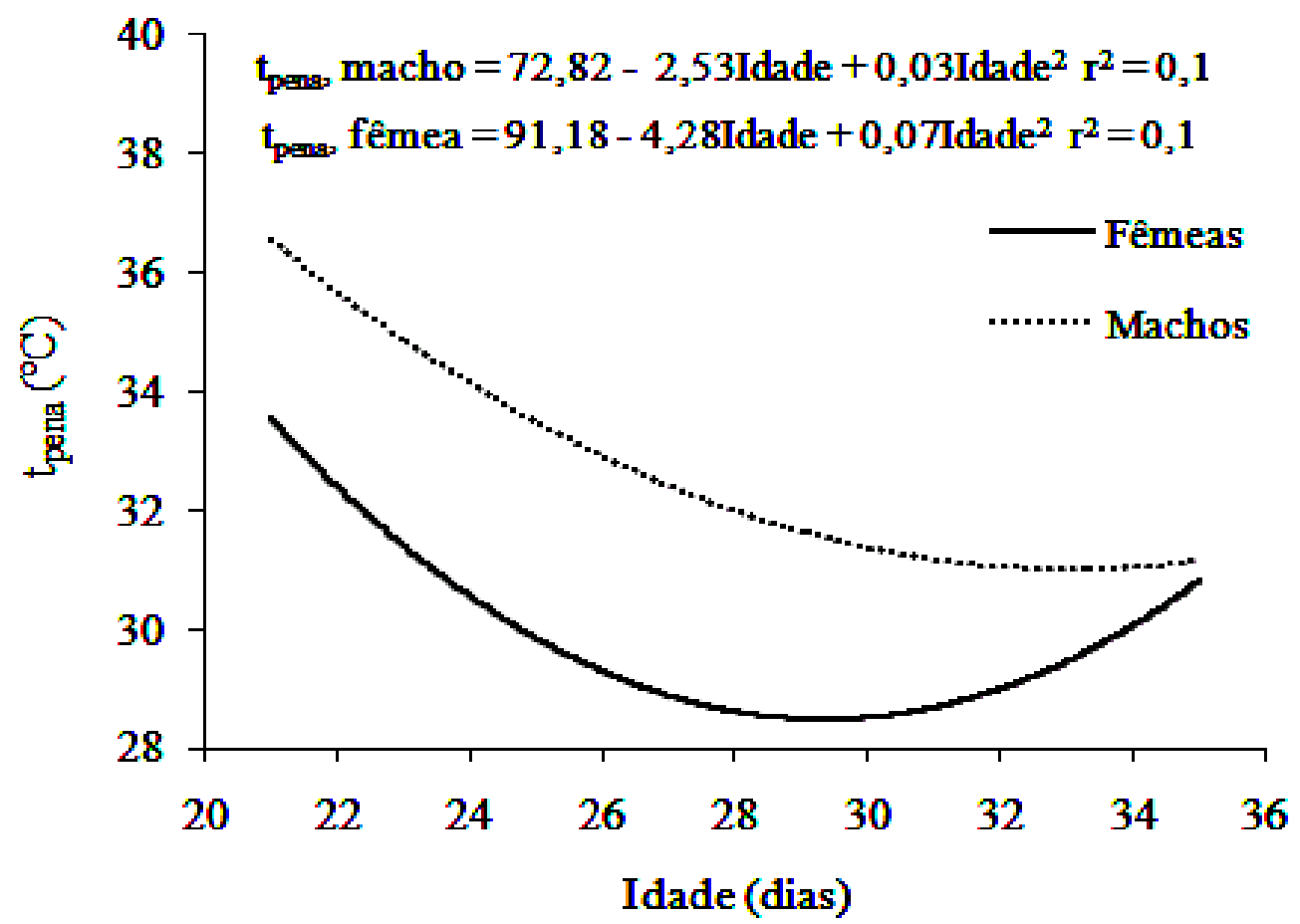

Figura 6. Temperatura da pena $\left(\mathrm{T}_{\text {pena }}\right)$ de frangos de corte segundo o sexo, em função da idade.

A.

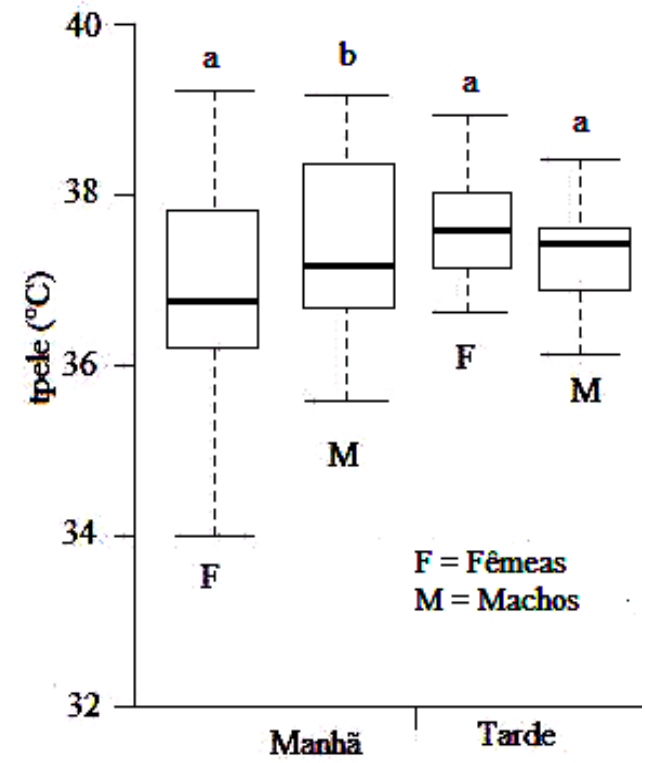

Periodo do dia
B.

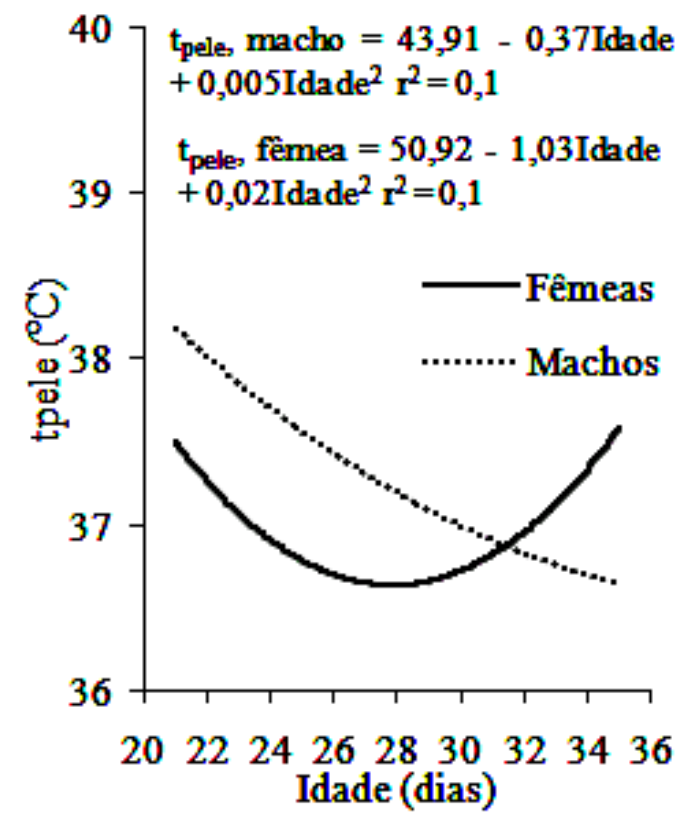

Figura 7. Temperatura da pele $\left(t_{\text {pele }}\right)$ de frangos de corte segundo o sexo, em função (A) do período do dia e (B) da idade. Médias seguidas de letras distintas diferem entre si $(\mathrm{P}<0,05)$ pelo teste $\mathrm{F}$. 
Efeito do ambiente de produção...

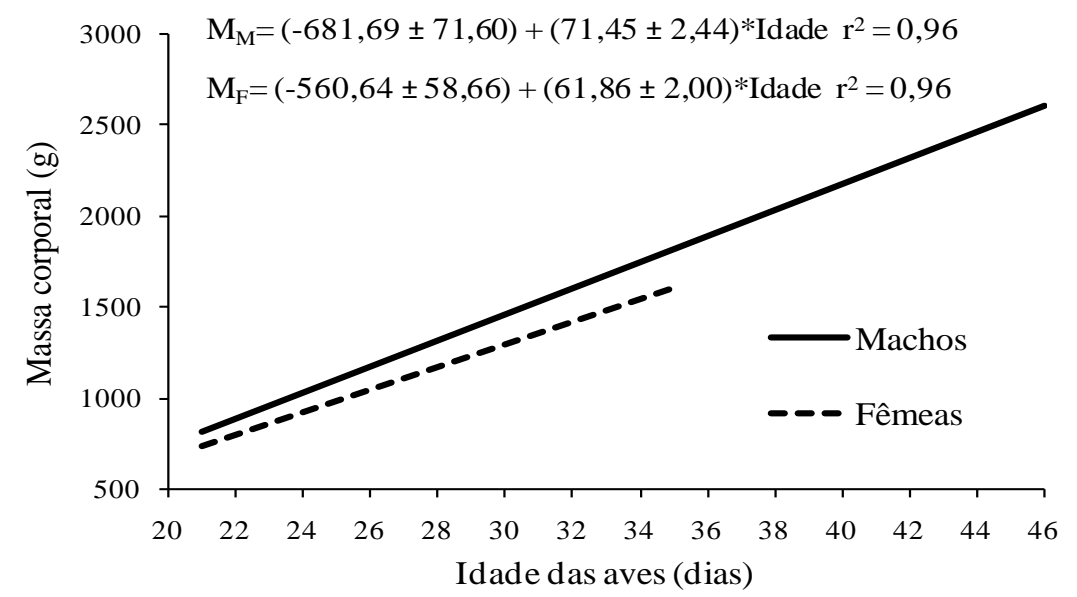

Figura 8. Massa corporal de frangos de corte machos $\left(\mathrm{M}_{\mathrm{M}}\right)$ e fêmeas $\left(\mathrm{M}_{\mathrm{F}}\right)$ em função da idade.

A.

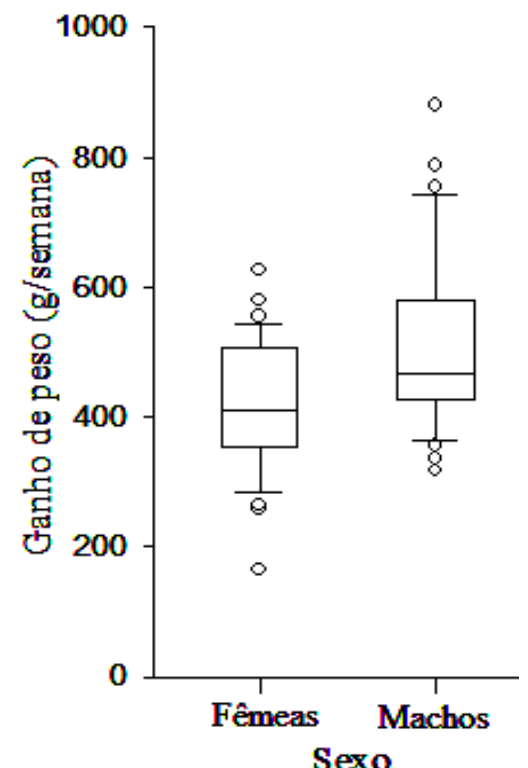

B.

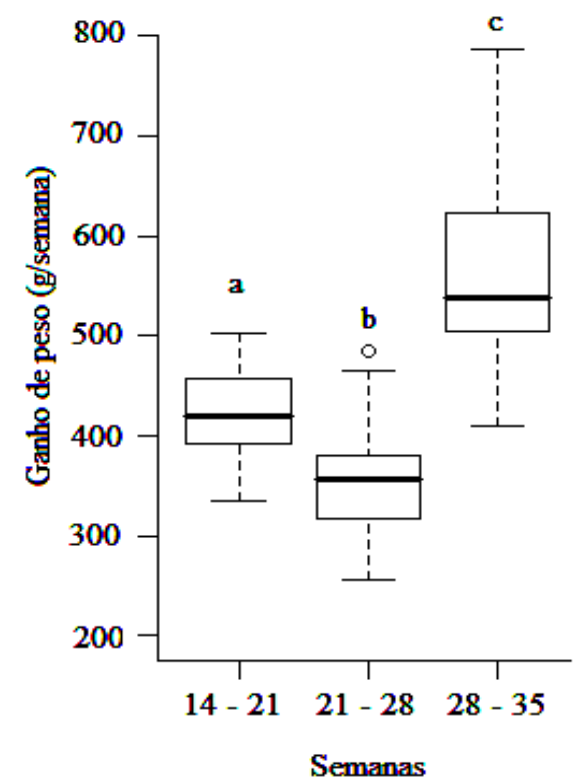

Figura 9. Ganho de peso semanal de frangos de corte em função (A) do sexo e (B) da semana de vida. Médias seguidas de letras distintas diferem entre si $(\mathrm{P}<0,05)$ pelo teste $\mathrm{F}$.

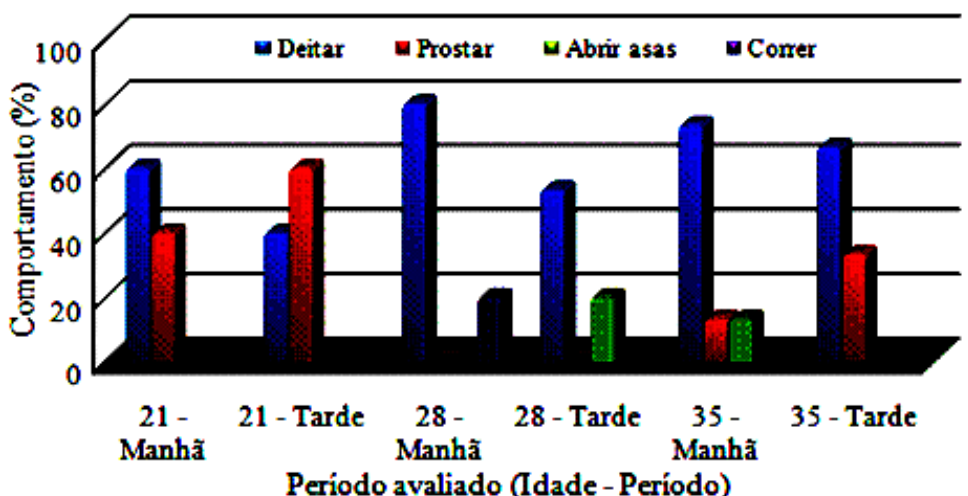

Figura 10. Comportamento dos frangos de corte em função do período do dia e da idade dos animais. 


\section{CONCLUSÕES}

Os frangos de corte de linhagem comercial machos apresentaram melhor desempenho produtivo que as fêmeas. Não se verificaram diferenças significativas entre os ambientes de produção no interior do galpão, que foram, no geral, inadequados à obtenção do máximo desempenho produtivo das aves.

\section{AGRADECIMENTOS}

Os autores agradecem à CAPES, à FAPEMIG e ao $\mathrm{CNPq}$, pelo suporte financeiro, e ao grupo Penalva, por permitir a realização deste experimento em suas instalações.

\section{REFÊRENCIAS BIBLIOGRÁFICAS}

ABREU, P.G.; ABREU, V.M.N.; COLDEBELLA, A. et al. Condições térmicas ambientais e desempenho de aves criadas em aviários com e sem o uso de forro. Arq. Bras. Med. Vet. Zootec., v.59, p.1014-1020, 2007.

BIZERAY, D.; ESTEVEZ, I.; LETERRIER, C. et al. Influence of increasing environmental complexity on the level of fearfulness, performance and leg condiction in broilers. Poult. Sci., v.81, p.767-773, 2002.

BOONE, M.A.; HUGHES, B.L. Wind velocity as it affects body temperature, water consumption during heat stress of roosters. Poult. Sci., v.50, p.1535-1537, 1971.

BUFFINGTON, D.E.; COLLASSO-AROCHO, A.; CANTON, G.H. et al. Black globe-humidity index (ITGU) as comfort equation for dairy cows. Trans. ASAE, v.24, p. 711-714. 1981

DOWNS, K.M.; LIEN, R.J.; HESS, J.B. et al. The effects of photoperiod length, light intensity, and feed energy on growth responses and meat yield of broilers. J. Appl. Poult. Res., v.15, p.406-416, 2006.

DOZIER III, W.A.; PURSWELL, J.L.; BRANTON, S.L. Growth responses of male broilers subjected to high air velocity for either twelve or twenty-four hours from thirty-seven to fifty-one days of age. J. Appl. Poult. Res., v.15, p.362-366, 2006.

FERREIRA, D.F. Sistema de análise estatística para dados balanceados - SISVAR. Lavras: UFLA/DEX, 2000.

FURLAN, R.L. Influência da temperatura na produção de frangos de corte. In: SIMPÓSIO BRASIL SUL DE AVICULTURA, 7., 2006, Chapecó. Anais... Chapecó: [s.n.], 2006. p. 104-135.

LEANDRO, N.S.M.; CUNHA, W.C.P.; STRINGHINI, J.H. et al. Influência do peso inicial de pintos de corte sobre o desempenho e o rendimento de carcaça de frangos e a viabilidade econômica da produção. Rev. Bras. Zootec., v.35, p.2314-2321, 2006.
LONGO, F. A.; SAKOMURA, N. K.; RABELLO, C. B. et al. Exigências energéticas para mantença e para o crescimento de frangos de corte. Rev. Bras. Zootec., v.35, p.119-125, 2006.

LU, Q.; WEN, J.; ZHANG, H. Effect of chronic heat exposure on fat deposition and meat quality in two genetic types of chicken. Poult. Sci. v.86, p.1059-1064, 2007.

MARCHINI, C.F.P.; SILVA, P.L.; NASCIMENTO, M.R.B.M. et al. Frequência respiratória e temperatura cloacal em frangos de corte submetidos à temperatura ambiente cíclica elevada. Arch. Vet. Sci., v.12, p.41- 46, 2007.

MEDEIROS, C.M.; BAÊTA, F.C.; OLIVEIRA, R.F.M. et al. Efeitos da temperatura, umidade relativa e velocidade do ar em frangos de corte. Eng. Agric., v.1, p.277-286, 2005.

MENEGALI, I.; TINÔCO, I.F.F.; BAÊTA, F.C. et al. Ambiente térmico e concentração de gases em instalações para frangos de corte no período de aquecimento. Rev. Bras. Eng. Agric. Ambient., v.13, supl., p.984-990, 2009.

NAZARENO, A.C.; PANDORFI, H.; ALMEIDA, G.L.P. et al. Avaliação do conforto térmico e desempenho de frangos de corte sob regime de criação diferenciado. Rev. Bras. Eng. Agric. Ambient., v.13, p.802-808, 2009.

OLIVEIRA, R.F.M.; DONZELE, J.L.; ABREU, M.L.T. et al. Efeitos da temperatura e da umidade relativa sobre o desempenho e o rendimento de cortes nobres de frangos de corte de 1 a 49 dias de idade. Rev. Bras. Zootec., v.35, p.797-803, 2006.

SAMPAIO, C.A.P.; CRISTANI, J.; DUBIELA, J.A. et al. Avaliação do ambiente térmico em instalação para crescimento e terminação de suínos utilizando os índices de conforto térmico nas condições tropicais. Cienc. Rural, v.34, p.785-790, 2004.

SILVA, M.A.N.; BARBOSA FILHO, J.A.; ROSÁRIO, M.F. et al. Fatores de estresse associados à criação de linhagens de avós de frangos de corte. Rev. Bras. Zootec., v.36, p.652-659, 2007a.

SILVA, M.A.N.; BARBOSA FILHO, J.A.; SILVA, C.J.M. et al. Avaliação do estresse térmico em condição simulada de transporte de frangos de corte. Rev. Bras. Zootec., v.36, p.1126-1130, 2007b.

STRINGHINI, J.H.; LABOISSIÉRE, M.; MURAMATSU, K. et al. Avaliação do Desempenho e Rendimento de Carcaça de Quatro Linhagens de Frangos de Corte Criadas em Goiás. Rev. Bras. Zootec., v.32, p.183-190, 2003. 